\title{
IMPLEMENTASI PLAN-DO-CHECK-ACT (PDCA) \\ BERBASIS KEY PERFORMANCE INDICATORS (KPI): STUDI KASUS DI SMP-SMA INTEGRAL AR-ROHMAH DAU MALANG
}

\author{
Poppy Rachman \\ Program Studi Manajemen Pendidikan Islam, Universitas Islam Zainul Hasan Genggong, \\ Probolinggo, Jawa Timur, Indonesia \\ Email: poppyrachman.inzah@gmail.com
}

DOI: http://doi.org/10.33650/al-tanzim.v4i2. 981

\begin{tabular}{l|l|l} 
Received: February 2020 & Accepted: August 2020 & Published: September 2020
\end{tabular}

\begin{abstract}
:
This research is to analyze the process of development of quality management by using the cycled approach of PDCA (Plan-Do-Check-Act) based on KPI (Key Performance Indicators). This research was conducted at SMP-SMA Integral Ar-Rohmah "Boarding School" Dau Malang by using descriptive qualitative methods. The object of this research is around 449 students at SMP-SMA Integral Ar-Rohmah Dau Malang. The research period is the even semester of the 2018/2019 school year. The results of this study can be concluded that; Planning (Plan), produces three KPI formulation products, namely; a) KPI monitoring; b) KPI filling formula; and c) KPI report card. Implementation (Do), by requiring all students to participate in filling the KPI monitoring form and activeness of the musyrif room in assisting the filling of KPI. Evaluation (Check) that has been carried out is by means of a random check (random) conducted by the room meeting from the results of filling KPI monitoring. The follow up (Act) is to publish KPI report cards.
\end{abstract}

Keywords: PDCA, key performance indicators, quality management

\begin{abstract}
Abstrak:
Penelitian ini berusaha menganalisis tentang proses pengembangan manajemen mutu dengan pendekatan siklus PDCA (Plan-Do-Check-Act) berbasis KPI (Key Performance Indicators). Penelitian ini dilakukan di SMP-SMA Integral Ar-Rohmah "Boarding School" Dau Malang. Metode penelitian ini menggunakan pendekatan kualitataif deskriptif. Objek penelitian ini adalah unit keasramaan yang meliputi seluruh santri SMP-SMA dengan total jumlah sebanyak 449 santri. Periode penelitiannya adalah semester genap tahun ajaran 2018/2019. Hasil dari penelitiannya menunjukkan bahwa; Perencanaan (Plan), menghasilkan tiga produk perumusan KPI, yakni; a)monitoring KPI; b) rumus pengisian KPI; dan c) rapot KPI. Pelaksanaan (Do), dengan mewajibkan seluruh santri untuk berpartisipasi dalam pengisian form monitoring KPI serta keaktifan musyrif kamar dalam mendampingi pengisian KPI. Evaluasi (Check) dilakukan dengan cara pengecekan acak (random) yang dilakukan musyrif kamar dari hasil pengisian monitoring KPI. Tindak lanjutnya (Act) dengan menerbitkan rapot KPI.
\end{abstract}

Kata Kunci: PDCA, key performance indicators, manajemen mutu 


\section{PENDAHULUAN}

Pada era globalisasi yang semakin berkembang saat ini, banyak lembaga pendidikan - khususnya lembaga pendidikan Islam - yang sudah mulai berbenah. Perubahan yang mereka lakukan dimulai dari pembenahan manajemen organisasi, pengembangan SDM (Sumber Daya Manusia) dengan sistem pengembangan yang berkesinambungan serta pembenahan di bidang sarana dan prasarana. Pembenahan dalam lingkup lembaga pendidikan merupakan suatu keharusan agar bisa menghadapi perkembangan zaman dan untuk pengembangan manajemen mutu suatu lembaga (Asare et al., 2007; Yeravdekar \& Behl, 2017).

Pepatah mengungkapkan bahwa sesuatu yang abadi dalam dunia ini adalah perubahan. Dari pepatah ini menunjukkan bahwa segala sesuatu di dunia pasti akan mengalami perubahan. Mulai dari perubahan zaman, perubahan kondisi masyarakat, bahkan sampai pada perubahan tekhnologi yang selalu berubah sesuai dengan perkembangan zaman (Muhaimin, 2009).

Mengamati hal tersebut, lembaga pendidikan haruslah mencari formula baru agar bisa memajukan lembaga pendidikannya untuk tetap eksis atau bahkan semakin berkembang. Hal yang sangat krusial untuk tetap dijaga adalah pengembangan SDM, karena SDM merupakan ujung tombak dari pengembangan suatu organisasi. Sumber daya manusia merupakan faktor yang sangat sentral dalam organisasi, apapun bentuk dan tujuannya, organisasi dibuat berdasarkan berbagai visi untuk kepentingan manusia.

Pentingnya Sumber Daya Manusia dalam suatu organisasi menuntut setiap organisasi mendapatkan SDM yang berkualitas dan produktif untuk menjalankan organisasi. Manajemen sumber daya manusia pada era informasi ini, menurut Dessler (2003) harus memiliki pemimpin organisasi yang mampu mengaitkan pelaksanaan manajemen sumber daya manusia dengan strategi organisasi untuk meningkatkan kinerja serta mengembangkan budaya organisasi mendukung penerapan inovasi.

PDCA adalah singkatan dari Plan, Do, Check dan Act, yaitu siklus peningkatan proses (process improvement) yang berkesinambungan atau secara terus menerus, seperti lingkaran yang tidak ada akhirnya. Suatu proses pemecahan masalah empat langkah yang umum digunakan dalam pengendalian kualitas adalah PDCA, singkatan dari "Plan, Do, Check, Act" (Rencanakan, Kerjakan, Pemeriksaan, Tindak lanjut). PDCA dikenal sebagai "siklus Shewhart", karena pertama kali dikemukakan oleh Walter Shewhart beberapa puluh tahun yang lalu. Namun dalam perkembangannya, analisis PDCA lebih sering disebut "siklus Deming". Hal ini disebabkan karena Deming adalah orang yang mempopulerkan penggunaannya dan memperluas penerapannya. Namun, Deming sendiri selalu merujuk metode ini sebagai siklus Shewhart, yang dianggap sebagai bapak pengendalian kualitas statistik. PDCA adalah cara yang bermanfaat untuk melakukan perbaikan secara terus menerus tanpa berhenti (Tannady, 2015).

SMP-SMA Integral Ar-Rohmah "Boarding School" Dau Malang merupakan lembaga pendidikan Islam yang selalu berinovasi untuk mengembangkan SDM yang dimiliki, baik SDM pendidik atau SDM peserta 
didik. Lembaga ini telah dua kali melaksanakan akreditasi, yakni akreditasi yang diselenggarakan oleh BAN-SM (Badan Akreditasi Nasional Sekolah Menengah) dan akreditasi PIBT (Pendidikan Islam Berbasis Tauhid) yang diselenggarakan oleh pimpinan pusat Hidayatullah. Hasil dari kedua akreditasi tersebut menunjukkan bahwa SMP-SMA Integral Ar-Rohmah "Boarding School" mendapatkan penilaian "A" dari penetapan hasil akreditasinya.

SMP-SMA Integral Ar-Rohmah "Boarding School" tidak lantas berpuas diri dengan capaian tersebut. Target yang ingin dicapai berikutnya ialah standarisasi internasional yakni ISO 9001. ISO (International Organization for Standarization) merupakan standar internasional di bidang sistem manajemen mutu. Suatu lembaga yang mendapatkan akreditasi ISO, dapat dikatakan telah memenuhi persyaratan internasional dalam hal manajemen penjaminan mutu (Asy'ari, 2015).

Sistem ISO 9001 berfokus pada efektivitas dan proses perbaikan yang berkelanjutan dengan menggunakan pendekatan siklus PDCA (Plan-Do-CheckAct), di mana setiap proses dilakukan dengan perencanaan yang matang, implementasi yang terukur dan jelas, dilakukan evaluasi dan analisis data yang akurat, serta tindakan perbaikan yang sesuai dengan monitoring pelaksanaannya, agar benar-benar bisa menyelesaikan masalah yang terjadi di organisasi (Ariani, 2013).

SMP-SMA Integral Ar-Rohmah "Boarding School" telah melakukan pengembangan manajemen mutu berbasis KPI (Key Performance Indicators). Hal ini didasarkan pada kajian lembaga terhadap pentingnya KPI, sebagaimana hasil penelitian Wadongo et al., (2010) yang menjelaskan bahwa KPI merupakan indikator kinerja utama sebagai alat navigasi penting yang digunakan oleh para manajer. Menurut Grover (2015), KPI ditujukan untuk memahami apakah organisasi mereka sedang mengarah pada kesuksesan atau sedang menjauhi jalur menuju kesuksesan melalui beberapa indikator. Menurut Marr (2015) indikator yang tepat akan menunjukan kinerja dan menampilkan wilayah-wilayah yang perlu mendapat perhatian pada organisasi atau lembaga tersebut.

Mengingat pentingnya Key Performance Indicators dalam aktivitas pengukuran kinerja bagi lembaga pendidikan, maka penelitian ini terfokus pada proses pengembangan manajemen mutu dengan pendekatan siklus PlanDo-Check-Act berbasis Key Performance Indicators di SMP-SMA Integral ArRohmah "Boarding School” Dau Malang.

\section{METODE PENELITIAN}

Penelitian ini dilakukan dengan menggunakan pendekatan kualitatif deskriptif, yang ditunjukkan untuk mendeskripsikan atau menggambarkan fenomena-fenomena yang ada (Sukmadinata, 2011), baik fenomena yang bersifat alamiah atau rekayasa manusia dari sudut atau perspektif partisipan. Teknik pengumpulan datanya dilakukan melalui observasi, wawancara, studi dokumenter, studi literatur.

Tahap analisis data di lapangan merupakan analisis yang dilakukan pada saat pengumpulan data berlangsung dan setelah selesai pengumpulan 
data dalam periode tetentu. Analisis data dilakukan terhadap keseluruhan data yang diperoleh dari sumber data melalui proses pengumpulan data yang terdiri dari observasi, wawancara mendalam dan studi dokumentasi. Dengan tiga tahapan, yaitu: display data, reduksi data, menarik kesimpulan dan verifikasi.

SMP-SMA Integral Ar-Rohmah "Boarding School" Dau Malang terdiri dari 3 unit organisasi yang berada di dalamnya, yakni unit akademik yang dipimpin oleh kepala sekolah, unit Madrasatul Qur'an (MQ) yang dipimpin oleh kepala $\mathrm{MQ}$, dan unit keasramaan yang dipimpin oleh kepala asrama. Subyek penelitian ini adalah unit keasramaan yang meliputi seluruh santri SMP-SMA Integral Ar-Rohmah "Boarding School" Dau Malang, mulai dari SMP kelas VII sampai SMA kelas XI dengan total jumlah santri sebanyak 449 santri. Periode penelitiannya adalah semester genap tahun ajaran 2018/2019.

\section{HASIL DAN PEMBAHASAN}

\section{Implementasi Perencanaan (Plan) dalam Pengembangan Manajemen Mutu Berbasis KPI}

Plan (Perencanaan) dimaknai sebagai aktivitas merencanakan sasaran (Goal = Tujuan) dan proses apa yang dibutuhkan untuk menentukan hasil yang sesuai dengan spesifikasi tujuan yang ditetapkan. Perencanaan ini dilakukan untuk mengidentifikasi terhadap permasalahan yang terjadi dan mengambil kesimpulan terhadap faktor-faktor yang mempengaruhi timbulnya permasalahan (Tannady et al., 2019).

Perencanaan dalam pengembangan manajemen mutu di unit keasramaan SMP-SMA Integral Ar-Rohmah "Boarding School" Dau Malang dengan merumuskan KPI (Key Performance Indicators) yang melibatkan dewan direksi, kepala unit, dan wakil kepala unit. Key performance indikator tidak hanya mengukur suatu panjang, waktu proses, maupun umur alat, namun lebih kepada ukuran dari suatu performance atau kinerja terhadap kesuksesan (Marr, 2015). Perumusan KPI ini dilakukan pada semester ganjil tahun ajaran 2018/2019. Penerapan dari perumusan KPI dilakukan pada semester genap tahun ajaran 2018/2019. Dari perumusan KPI yang disahkan oleh dewan direksi dan seluruh kepala unit menghasilkan tiga produk perumusan KPI, yakni; a) monitoring KPI; b) rumus pengisian KPI; dan c) raport KPI.

a. Monitoring KPI

Monitoring KPI atau biasa disebut dengan "muhasabah yaumiyah" adalah monitoring yang berbentuk form penilaian diri dengan verifikasi. Form penilaian ini diisi oleh santri dengan verifikasi oleh pendamping atau "Musyrif kamar". Monitoring KPI ini terdiri dari 25 sub-variabel dengan interval pengisian 1-4. Pengisian dilakukan selama satu bulan penuh dengan total jumlah hari dari bulan tersebut. 
Tabel 1 : Variabel KPI Insan Kamil Keasramaan SMP-SMA Integral Ar-Rohmah "Boarding School" Dau Malang

\begin{tabular}{|c|c|c|}
\hline $\begin{array}{l}\text { Variabel Karakter } \\
\text { Insan Kamil }\end{array}$ & Variabel & Sub-Variabel \\
\hline \multirow{17}{*}{ Ruhiyah } & \multirow{3}{*}{ Aqidah Sohihah } & Muhasabah \\
\hline & & MenghadiriTa'lim \\
\hline & & Menjaga diri dari Kesombongan \\
\hline & \multirow{4}{*}{$\begin{array}{l}\text { Akhlaqul } \\
\text { Karimah }\end{array}$} & Adab kepada Allah SWT \\
\hline & & Adab terhadap Orang Tua/Asatidzah \\
\hline & & Adab Pribadi \\
\hline & & Adab Terhadap Teman \\
\hline & \multirow{9}{*}{$\begin{array}{l}\text { Mujiddun fil } \\
\text { Ibadah }\end{array}$} & Sholat Lail \\
\hline & & Sholat Shubuh \\
\hline & & Sholat Dzuhur \\
\hline & & Sholat Ashar \\
\hline & & Sholat Maghrib \\
\hline & & Sholat Isya' \\
\hline & & Sholat Rawatib \\
\hline & & Dzikir \\
\hline & & Puasa Sunnah \\
\hline & $\begin{array}{l}\text { Dakwah bil } \\
\text { Hikmah }\end{array}$ & Melakukan Amar Ma'ruf Nahi Munkar \\
\hline \multirow{6}{*}{ Jismiyah } & Pandu & Tarbiyah Qiyadiyah (Kepemimpinan) \\
\hline & Hidayatullah & Tarbiyah Ijtimaiyah (Kemasyarakatan) \\
\hline & & $\begin{array}{l}\text { Piket Harian Asrama } \\
\text { Jam Tidur Malam }\end{array}$ \\
\hline & Kedisiplinan & Ketepatan Berangkat Sekolah \\
\hline & & $\begin{array}{l}\text { Perijinan Kunjungan Wali Santri } \\
\text { Kebersihan dan Kerapian Diri }\end{array}$ \\
\hline & $\begin{array}{l}\text { Bi'ah Bahasa } \\
\text { Arab }\end{array}$ & Konsistensi Penggunaan Bahasa Arab \\
\hline
\end{tabular}

Data pada Table 1 tersebut menunjukkan bahwa karakter insan kamil keasramaan terdiri dari Ruhiyah dan Jismiyah. Karakter Ruhiyah terdapat unsur Aqidah Sohihah, Akhlakul Karimah, Mujiddun fil ibadah dan dakwah bil hikmah, sedangkan karakter jismiyah terdapat unsur pandu hidayatullah, kedisiplinan dan Bi'ah bahasa arab.

b. Rumus Pengisian KPI

Rumus pengisian KPI ini adalah acuan untuk pengisian form monitoring KPI. Dari 25 sub-variabel yang tertera dalam form monitoring, santri harus mengisi satu persatu dari seluruh sub-variable tersebut. Pengisian monitoring menggunakan skala Likert dengan interval 1-4. Jadi santri harus mengisi form monitoring dengan mengacu 
pada rumus pengisian KPI dan memilih pilihan yang sudah tertera pada rumus pengisian KPI antara interval 1-4.

Tabel 2 : Rumus Pengisian KPI (Variabel Ruhiyah)

\begin{tabular}{|c|c|c|c|c|c|c|}
\hline \multirow{2}{*}{ Variabel } & \multirow{2}{*}{ Sub-Variabel } & \multirow{2}{*}{ Keterangan } & \multicolumn{4}{|c|}{ Skala Linkert } \\
\hline & & & 1 & 2 & 3 & 4 \\
\hline \multirow{3}{*}{$\begin{array}{l}\text { Aqidah } \\
\text { Sohihah }\end{array}$} & Muhasabah & $\begin{array}{l}\text { Ketepatan } \\
\text { waktu }\end{array}$ & $\begin{array}{l}\text { T } 10 \\
\text { mnt }\end{array}$ & $\begin{array}{l}\text { T } 5 \\
\text { mnt }\end{array}$ & HTW & HSW \\
\hline & MenghadiriTa'lim & $\begin{array}{l}\text { Ketepatan } \\
\text { waktu }\end{array}$ & $\begin{array}{l}\text { T } 10 \\
\text { mnt }\end{array}$ & $\begin{array}{l}\text { T } 5 \\
\text { mnt }\end{array}$ & HTW & HSW \\
\hline & $\begin{array}{l}\text { Menjaga diri dari } \\
\text { Kesombongan }\end{array}$ & $\begin{array}{l}\text { Tidak } \\
\text { sombong }\end{array}$ & Lebih $2 x$ & $\begin{array}{c}\text { Pernah } \\
2 x\end{array}$ & $\begin{array}{l}\text { Pernah } \\
1 x\end{array}$ & $\begin{array}{c}\text { menigl } \\
\text { kan }\end{array}$ \\
\hline \multirow{17}{*}{$\begin{array}{l}\text { Akhlaqul } \\
\text { Karimah }\end{array}$} & \multirow{4}{*}{$\begin{array}{l}\text { Adab kepada Allah } \\
\text { SWT }\end{array}$} & $\begin{array}{l}\text { Mendengrkn } \\
\text { Adzan }\end{array}$ & $\begin{array}{l}\text { Tidak } \\
\text { prnah }\end{array}$ & Jarang & Sering & Selalu \\
\hline & & $\begin{array}{l}\text { Menjawab } \\
\text { Adzan }\end{array}$ & $\begin{array}{l}\text { Tidak } \\
\text { prnah }\end{array}$ & Jarang & Sering & Selalu \\
\hline & & $\begin{array}{l}\text { Berdoa stlh } \\
\text { adzan }\end{array}$ & $\begin{array}{l}\text { Tidak } \\
\text { prnah }\end{array}$ & Jarang & Sering & Selalu \\
\hline & & Tertib sholat & $\begin{array}{l}\text { Tidak } \\
\text { prnah }\end{array}$ & Jarang & Sering & Selalu \\
\hline & \multirow{4}{*}{$\begin{array}{l}\text { Adab terhadap } \\
\text { Orang } \\
\text { Tua/Asatidzah }\end{array}$} & Patuh & $\begin{array}{l}\text { Tidak } \\
\text { prnah }\end{array}$ & Jarang & Sering & Selalu \\
\hline & & Menghormati & $\begin{array}{l}\text { Tidak } \\
\text { prnah }\end{array}$ & Jarang & Sering & Selalu \\
\hline & & $\begin{array}{l}\text { Bersabar atas } \\
\text { Kekurangan }\end{array}$ & $\begin{array}{l}\text { Tidak } \\
\text { prnah }\end{array}$ & Jarang & Sering & Selalu \\
\hline & & $\begin{array}{l}\text { Berbicara } \\
\text { Santun }\end{array}$ & $\begin{array}{l}\text { Tidak } \\
\text { prnah }\end{array}$ & Jarang & Sering & Selalu \\
\hline & \multirow{4}{*}{ Adab Pribadi } & $\begin{array}{l}\text { Berperilaku } \\
\text { Jujur }\end{array}$ & $\begin{array}{l}\text { Tidak } \\
\text { prnah }\end{array}$ & Jarang & Sering & Selalu \\
\hline & & $\begin{array}{l}\text { Berbicara } \\
\text { Sopan }\end{array}$ & $\begin{array}{l}\text { Tidak } \\
\text { prnah }\end{array}$ & Jarang & Sering & Selalu \\
\hline & & Adab Makan & $\begin{array}{l}\text { Tidak } \\
\text { prnah }\end{array}$ & Jarang & Sering & Selalu \\
\hline & & $\begin{array}{l}\text { Adab } \\
\text { Berpakaian }\end{array}$ & $\begin{array}{l}\text { Tidak } \\
\text { prnah }\end{array}$ & Jarang & Sering & Selalu \\
\hline & \multirow{4}{*}{$\begin{array}{l}\text { Adab Terhadap } \\
\text { Teman }\end{array}$} & $\begin{array}{l}\text { Berbicara } \\
\text { santun }\end{array}$ & $\begin{array}{l}\text { Tidak } \\
\text { prnah }\end{array}$ & Jarang & Sering & Selalu \\
\hline & & Bersabar & $\begin{array}{l}\text { Tidak } \\
\text { prnah }\end{array}$ & Jarang & Sering & Selalu \\
\hline & & $\begin{array}{l}\text { Tidak } \\
\text { Memakai } \\
\text { Hak Milik } \\
\text { Orang Lain }\end{array}$ & $\begin{array}{l}\text { Tidak } \\
\text { prnah }\end{array}$ & Jarang & Sering & Selalu \\
\hline & & $\begin{array}{l}\text { Tolong } \\
\text { menolong }\end{array}$ & $\begin{array}{l}\text { Tidak } \\
\text { prnah }\end{array}$ & Jarang & Sering & Selalu \\
\hline & Sholat Lail & Sholat Lail & Tidak & - & - & Sholat \\
\hline
\end{tabular}




\begin{tabular}{|c|c|c|c|c|c|c|}
\hline \multirow{11}{*}{$\begin{array}{l}\text { Mujiddun } \\
\text { fil Ibadah }\end{array}$} & \multicolumn{6}{|c|}{ sholat } \\
\hline & Sholat Shubuh & $\begin{array}{l}\text { Ketepatan } \\
\text { Waktu }\end{array}$ & $\begin{array}{c}\text { Tdk } \\
\text { jamaah }\end{array}$ & $\begin{array}{c}\text { Terlam } \\
\text { bat }\end{array}$ & $\begin{array}{c}\text { Lengkap } \\
\text { brsma } \\
\text { Imam }\end{array}$ & $\begin{array}{c}\text { Takbirat } \\
\text { ul Ihram } \\
\text { brsma } \\
\text { Imam }\end{array}$ \\
\hline & Sholat Dzuhur & $\begin{array}{l}\text { Ketepatan } \\
\text { Waktu }\end{array}$ & $\begin{array}{c}\text { Tdk } \\
\text { jamaah }\end{array}$ & $\begin{array}{c}\text { Terlam } \\
\text { bat }\end{array}$ & $\begin{array}{c}\text { Lengkap } \\
\text { brsma } \\
\text { Imam }\end{array}$ & $\begin{array}{l}\text { Takbir } \\
\text { Ihram } \\
\text { brsma } \\
\text { Imam }\end{array}$ \\
\hline & Sholat Ashar & $\begin{array}{l}\text { Ketepatan } \\
\text { Waktu }\end{array}$ & $\begin{array}{c}\text { Tdk } \\
\text { jamaah }\end{array}$ & $\begin{array}{c}\text { Terlam } \\
\text { bat }\end{array}$ & $\begin{array}{c}\text { Lengkap } \\
\text { brsma } \\
\text { Imam }\end{array}$ & $\begin{array}{l}\text { Takbir } \\
\text { Ihram } \\
\text { brsma } \\
\text { Imam }\end{array}$ \\
\hline & Sholat Maghrib & $\begin{array}{l}\text { Ketepatan } \\
\text { Waktu }\end{array}$ & $\begin{array}{c}\text { Tdk } \\
\text { jamaah }\end{array}$ & $\begin{array}{c}\text { Terlam } \\
\text { bat }\end{array}$ & $\begin{array}{c}\text { Lengkap } \\
\text { brsma } \\
\text { Imam }\end{array}$ & $\begin{array}{l}\text { Takbir } \\
\text { Ihram } \\
\text { brsma } \\
\text { Imam }\end{array}$ \\
\hline & Sholat Isya' & $\begin{array}{l}\text { Ketepatan } \\
\text { Waktu }\end{array}$ & $\begin{array}{c}\text { Tdk } \\
\text { jamaah }\end{array}$ & $\begin{array}{c}\text { Terlam } \\
\text { bat }\end{array}$ & $\begin{array}{c}\text { Lengkap } \\
\text { brsma } \\
\text { Imam }\end{array}$ & $\begin{array}{l}\text { Takbir } \\
\text { Ihram } \\
\text { brsma } \\
\text { Imam }\end{array}$ \\
\hline & Sholat Rawatib & $\begin{array}{l}\text { Jumlah } \\
\text { rakaat }\end{array}$ & $\begin{array}{l}\text { Tdk } \\
\text { sholat }\end{array}$ & $\begin{array}{c}2 \\
\text { rakaat } \\
\text { sehari }\end{array}$ & $\begin{array}{c}4 \\
\text { rakaat } \\
\text { sehari }\end{array}$ & $\begin{array}{c}6 \\
\text { rakaat } \\
\text { sehari }\end{array}$ \\
\hline & Drikir & $\begin{array}{l}\text { Dzikir ba'da } \\
\text { sholat }\end{array}$ & $\begin{array}{c}\text { Krng dr } \\
3 \\
\end{array}$ & $\begin{array}{c}3 \mathrm{x} \\
\text { sehari }\end{array}$ & $\begin{array}{c}4 x \\
\text { sehari } \\
\end{array}$ & $\begin{array}{c}5 x \\
\text { sehari } \\
\end{array}$ \\
\hline & Dzikır & Dzikir Pagi & Tidak & - & - & $\mathrm{Ya}$ \\
\hline & & Dzikir Petang & Tidak & - & - & $\mathrm{Ya}$ \\
\hline & Puasa Sunnah & $\begin{array}{l}\text { Senin \& } \\
\text { Kamis }\end{array}$ & Tidak & - & - & $\mathrm{Ya}$ \\
\hline $\begin{array}{l}\text { Dakwah bil } \\
\text { Hikmah }\end{array}$ & $\begin{array}{l}\text { Melakukan Amar } \\
\text { Ma'ruf Nahi } \\
\text { Munkar }\end{array}$ & $\begin{array}{l}\text { Melakukan } \\
\text { Amar Ma'ruf } \\
\text { Nahi Munkar }\end{array}$ & Jarang & Pernah & Sering & Selalu \\
\hline
\end{tabular}

Tabel 3 : Rumus Pengisian KPI (Variabel Jismiyah)

\begin{tabular}{|c|c|c|c|c|c|c|}
\hline \multirow{2}{*}{ Variabel } & \multirow{2}{*}{ Sub-Variabel } & \multirow{2}{*}{ Keterangan } & \multicolumn{4}{|c|}{ Skala Linkert } \\
\hline & & & 1 & 2 & 3 & 4 \\
\hline \multirow{2}{*}{$\begin{array}{l}\text { Pandu } \\
\text { Hidayatu } \\
\text { llah }\end{array}$} & Muhasabah & $\begin{array}{l}\text { Memimpin diri } \\
\text { sendiri }\end{array}$ & Tidak & - & - & Bisa \\
\hline & $\begin{array}{l}\text { Menjaga diri dari } \\
\text { Kesombongan }\end{array}$ & $\begin{array}{l}\text { Partisipasi kerja } \\
\text { bakti }\end{array}$ & $1 x$ & $2 x$ & $3 x$ & $4 x$ \\
\hline \multirow{3}{*}{$\begin{array}{l}\text { Kedisipli } \\
\text { nan }\end{array}$} & Piket Harian Asrama & Kehadiran & Tidak & - & - & $\mathrm{Ya}$ \\
\hline & Jam Tidur Malam & Awal tidur & $\begin{array}{c}\text { Tdk } \\
\text { tepat }\end{array}$ & - & - & Tepat \\
\hline & & Bangun tidur & $\begin{array}{l}\text { Tdk } \\
\text { tepat }\end{array}$ & - & - & Tepat \\
\hline
\end{tabular}




\begin{tabular}{|c|c|c|c|c|c|c|}
\hline & $\begin{array}{l}\text { Ketepatan Berangkat } \\
\text { Sekolah }\end{array}$ & $\begin{array}{l}\text { Ketepatan } \\
\text { waktu }\end{array}$ & $\begin{array}{l}\text { Tlt Lbh } \\
10 \text { mnt } \\
\text { dari bel }\end{array}$ & $\begin{array}{l}\text { Tlt } 10 \\
\text { mnt }\end{array}$ & Pas bel & $\begin{array}{l}\text { Sblm } \\
\text { bel }\end{array}$ \\
\hline & \multirow{2}{*}{$\begin{array}{l}\text { Perijinan Kunjungan } \\
\text { Wali Santri }\end{array}$} & $\begin{array}{l}\text { Meninggalkan } \\
\text { Pondok }\end{array}$ & $\begin{array}{l}\text { Tanpa } \\
\text { ijin }\end{array}$ & - & - & Ijin \\
\hline & & $\begin{array}{l}\text { Kembali ke } \\
\text { pondok }\end{array}$ & $\begin{array}{l}\text { Tdk tpt } \\
\text { waktu }\end{array}$ & - & - & $\begin{array}{c}\text { Tpt } \\
\text { waktu }\end{array}$ \\
\hline & \multirow{5}{*}{$\begin{array}{l}\text { Kebersihan dan } \\
\text { Kerapian Diri }\end{array}$} & $\begin{array}{l}\text { Kebersihan } \\
\text { Badan }\end{array}$ & $\begin{array}{c}\text { Tdk } \\
\text { bersih }\end{array}$ & - & - & Bersih \\
\hline & & $\begin{array}{l}\text { Kebersihan } \\
\text { Pakaian }\end{array}$ & $\begin{array}{c}\text { Tdk } \\
\text { bersih }\end{array}$ & - & - & Bersih \\
\hline & & $\begin{array}{l}\text { Kebersihan } \\
\text { Tmpat Tidur }\end{array}$ & $\begin{array}{c}\text { Tdk } \\
\text { bersih }\end{array}$ & - & - & Bersih \\
\hline & & $\begin{array}{l}\text { Kerapian } \\
\text { Almari }\end{array}$ & Tdk rapi & - & - & Rapi \\
\hline & & $\begin{array}{l}\text { Kerapian } \\
\text { Tempat Tidur }\end{array}$ & Tdk rapi & - & - & Rapi \\
\hline $\begin{array}{l}\text { Bi'ah } \\
\text { Bahasa }\end{array}$ & $\begin{array}{l}\text { Konsistensi } \\
\text { penggunaan } \\
\text { bahasa arab }\end{array}$ & Konsistensi & Jarang & $\begin{array}{l}\text { Kadan } \\
\mathrm{g}\end{array}$ & Sering & Selalu \\
\hline
\end{tabular}

T : Terlambat

HTW : Hadir Tepat Waktu

HSW : Hadir Sebelum Waktu

Dari data table 2 dan 3 menunjukkan bahwa rumus pengisian KPI ditinjau dari kedua variable yaitu ruhiyah dan jismiyah dengan menggunakan skala linkert.

c. Raport KPI

Data yang disajikan dalam rapot KPI adalah nama santri, kelas, kamar, periode rapot, variabel karakter, sub-variabel, target capaian, pengukuran skala, bobot, hasil, bobot di kali hasil, total indeks prestasi, rating nilai dan definisi, serta tanda tangan (wali santri, musyrif kamar, kepala keasramaan). Berikut disajikan rating nilai dan definisi yang diterangkan dalam rapot KPI, predikat, pencapaian KPI dan definisi indeks prestasi.

Tabel 4 : Rating Nilai dan Definisi

\begin{tabular}{lccc}
\hline & \multicolumn{3}{c}{ Rating Nilai dan Definisi } \\
\hline \multirow{4}{*}{ KKM } & PREDIKAT & Pencapaian KPI & Definisi Indeks Prestasi \\
\cline { 2 - 4 } & A & $3.51 \leq x \leq 4.00$ & Sangat Memuaskan \\
& B & $2.81 \leq x<3.50$ & Memuaskan \\
& C & $2.01 \leq x<2.80$ & Cukup \\
& D & $0 \% \leq x<2.00$ & Kurang \\
\hline
\end{tabular}


Dari data Tabel 4 menunjukkan bahwa rating nilai dan definisi KKM (Kriteria Ketuntasan Minimal) ditandai dengan pemberian Predikat A jika pencapaian KPI $3.51 \leq x \leq 4.00$ (sangat memuaskan) dan predikat D jika pencapaian KPI $0 \% \leq x<2.00$ (Kurang).

\section{Implementasi Pelaksanaan (Do) dalam Pengembangan Manajemen Mutu Berbasis KPI}

Pelaksanaan manajemen mutu berbasis KPI yang telah dilakukan di unit keasramaan SMP-SMA Integral Ar-Rohmah "Boarding School" Dau Malang dengan menerapkan pengisian monitoring KPI kepada seluruh santri. Pengisian monitoring ini dilakukan oleh seluruh santri dengan didampingi oleh musyrif kamar. Jadwal pengisian monitoring KPI ini adalah pada jam 20.30 WIB sampai jam 21.00 WIB. Pengisian monitoring ini dengan konsep kejujuran sesuai dengan fakta yang telah dilakukan oleh santri dalam kegiatannya selam satu hari penuh, dimulai dari bangun tidur dipagi hari sampai menjelang tidur dimalam hari. Metode pengisiannya dengan berkelompok pada masing-masing kamar dan didampingi oleh musyrif kamarnya. Apabila telah dilakukan pengisian oleh santri maka pendamping kamar akan mengecek hasil dari pengisian santri tersebut apakah sesuai dengan yang telah dilakukan oleh santri selama satu hari penuh.

Partisipasi santri dalam pengisian KPI cukup signifikan dikarenakan seluruh tim manajemen dan kemusyrifan memberikan pendapingan yang sangat baik dalam penerapan pengisian KPI. Pada bulan desember seluruh santri berpatisipasi untuk mengisi form monitoring KPI. Pada bulan berikutnya ada santri kelas VII dan kelas VIII yang mutasi keluar dikarenakan ada udzur yang mengharuskan mereka untuk pindah sekolah dari SMP Integral ArRohmah "Boarding School” Dau Malang. Secara keseluruhan partisipasi santri dan pengurus keasramaan sangat baik dalam melaksanakan pengisian KPI. Dengan artian implementasi teori PDCA (Do) yang ada di SMP-SMA Integral Ar-Rohmah "Boarding School” Dau Malang dapat dilaksanakan dengan baik.

Tabel 5 : Partisipasi Pengisian KPI

\begin{tabular}{cccccccc}
\hline \multirow{2}{*}{ Kelas } & \multirow{2}{*}{$\begin{array}{c}\text { Jumlah } \\
\text { santri }\end{array}$} & $\begin{array}{c}\text { Dese } \\
\text { mber }\end{array}$ & Januari & $\begin{array}{c}\text { Februar } \\
\text { i }\end{array}$ & Maret & April & Mei \\
\hline $\begin{array}{c}\text { SMP - } \\
\text { VII }\end{array}$ & 142 & 142 & 141 & 141 & 141 & 141 & 141 \\
\hline $\begin{array}{c}\text { SMP - } \\
\text { VIII }\end{array}$ & 122 & 122 & 121 & 121 & 121 & 121 & 121 \\
\hline SMP - IX & 85 & 85 & 85 & 85 & 85 & 85 & 85 \\
\hline SMA - X & 58 & 58 & 58 & 58 & 58 & 58 & 58 \\
\hline SMA - XI & 42 & 42 & 42 & 42 & 42 & 42 & 42 \\
\hline Total & 449 & 449 & 447 & 447 & 447 & 447 & 447 \\
Total \% & $100 \%$ & $100 \%$ & $99,55 \%$ & $99,55 \%$ & $99,55 \%$ & $99,55 \%$ & $99,55 \%$ \\
\hline
\end{tabular}


Dari data tabel 5 menunjukkan bahwa partisipasi pengisian KPI mengalami penurunan di bulan Januari - Mei yaitu sebesar 0,45\% pada SMP kelas VII dan VIII.

\section{Implementasi Evaluasi (Check) dalam Pengembangan Manajemen Mutu Berbasis KPI}

Check (evaluasi) artinya melakukan evaluasi dan menganalisis terhadap sasaran dan proses serta melaporkan hasil. Membandingkan kualitas hasil produksi dengan standart yang telah ditetapkan, bersadarkan penelitian diperoleh data kegagalan dan kemudian memindai penyebab kegagalan (Tannady, 2015).

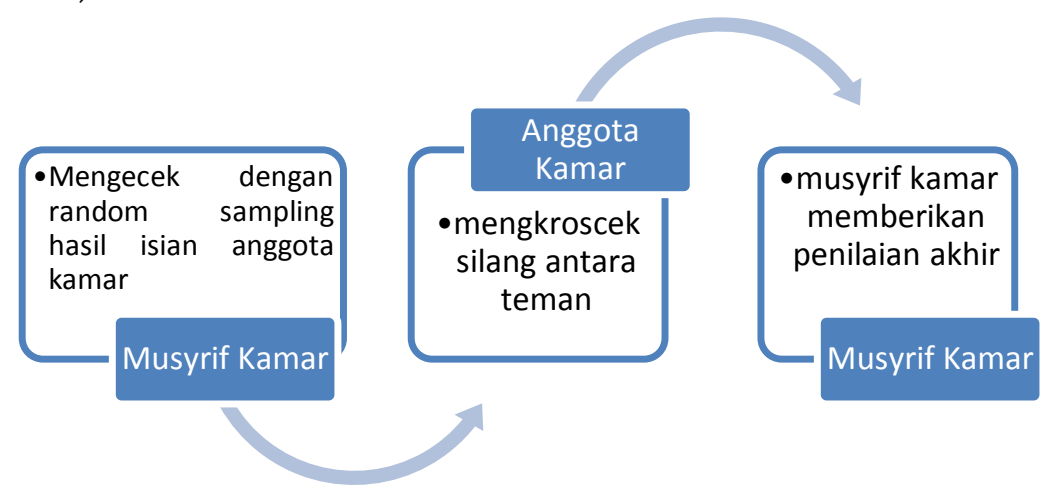

\section{Gambar 1 : Proses evaluasi KPI}

Gambar 1 menunjukkan pelaksanaan evaluasi manajemen mutu berbasis KPI yang telah dilakukan di unit keasramaan SMP-SMA Integral Ar-Rohmah "Boarding School" Dau Malang dengan menerapkan evaluasi berkelanjutan. Evaluasi pertama yang dilakukan adalah di waktu pengisian monitoring yang dilakukan pada waktu pengisian monitoring KPI malam hari. Jika ada hal yang tidak sesuai dengan kenyataan yang telah dilakukan oleh santri, maka pendamping kamar akan langsung mengevaluasi pengisian yang dilakukan oleh santri. Evaluasi kedua adalah evaluasi yang dilakukan oleh teman satu kamar yang akan mengkroscek silang dari kegiatan yang dilakukan antara temannya yang lain. Jika salah satu temannya menganggap tidak sesuai dengan kenyataanya, maka santri yang lain akan mengevaluasi dari kegiatan yang telah dilakukan oleh santri tersebut.

\section{Implementasi Tindak lanjut (Act) dalam Pengembangan Manajemen Mutu Berbasis KPI}

Action (tindak lanjut/ penyesuaian)artinya melakukan evaluasi total terhadap hasil sasaran dan proses dan menindaklanjuti dengan perbaikanperbaikan. Jika ternyata yang telah dikerjakan masih ada yang kurang atau belum sempurna, melakukan tindak lanjut (action) untuk memperbaikinya guna menghindari timbulnya kembali masalah yang sama atau menetapkan sasaran baru guna perbaikan berikutnya (Tannady, 2015).

Tindak lanjut dari proses pelaksanaan manajemen mutu berbasis KPI yang telah dilakukan di unit keasramaan SMP-SMA Integral Ar-Rohmah "Boarding School" Dau Malang dengan menerbitkan rapot KPI keasramaan. 
Pengolahan rapot ini melalui 3 tahapan pengolahan;

Pertama penginputan data awal. penginputan data disini dilakukan oleh pendamping kamar sesuai dengan apa yang telah ditulis oleh santri pada form pengisian monitoring KPI.

Kedua pengolahan data. dari data yang telah diinput oleh pendamping kamar, maka data tersebut akan diserahkan kepada tim pengolah data. Tim pengolah data akan mengkonfersi data tersebut menjadi database KPI. Database tersebut diolah dalam file exel dan akan dikonfersi dalam bentuk format mailing ke dalam format rapot berbentuk word dokumen.

Ketiga adalah proses pencetakan rapot yang di telah dimailing dalam bentuk word dokumen. Rapot tersebut akan dicek kembali sebelum ditanda tangani oleh musyrif kamar dan kepala keasramaan. Rapot tersebut akan diserahkan kepada wali santri pada jadwal kunjungan yang telah dijadwalkan setiap bulannya.

Tabel 6 : Rerata Indeks Prestasi

\begin{tabular}{ccccccc}
\hline \multirow{2}{*}{ Kelas } & \multicolumn{6}{c}{ Rerata Indeks Prestasi } \\
\cline { 2 - 7 } & Desember & Januari & Februari & Maret & April & Mei \\
\hline $\begin{array}{c}\text { SMP - } \\
\text { VII }\end{array}$ & 3,34 & 3,48 & 3,56 & 3,69 & 3,81 & 3,87 \\
\hline $\begin{array}{c}\text { SMP - } \\
\text { VIII }\end{array}$ & 3,29 & 3,43 & 3,51 & 3,64 & 3,76 & 3,82 \\
\hline SMP - IX & 3,39 & 3,53 & 3,61 & 3,74 & 3,86 & 3,89 \\
\hline SMA - X & 3,35 & 3,49 & 3,57 & 3,70 & 3,82 & 3,88 \\
\hline SMA - XI & 3,32 & 3,46 & 3,54 & 3,67 & 3,79 & 3,85 \\
\hline Total & 3,34 & 3,48 & 3,56 & 3,69 & 3,81 & 3,86 \\
\hline
\end{tabular}

Jika mengacu pada data rerata indeks prestasi di atas, maka dapat disimpulkan bahwa pencapaian nilai di bulan Desember 3,34 dan Januari 3,48 dengan definisi nilai (“B”-Memuaskan), pada bulan Februari 3,56, Maret 3,69, April 3,81, dan Mei 3,86 dengan definisi nilai ("A"-Sangat Memuaskan).

Diagram 1 : Rerata Indeks Prestasi

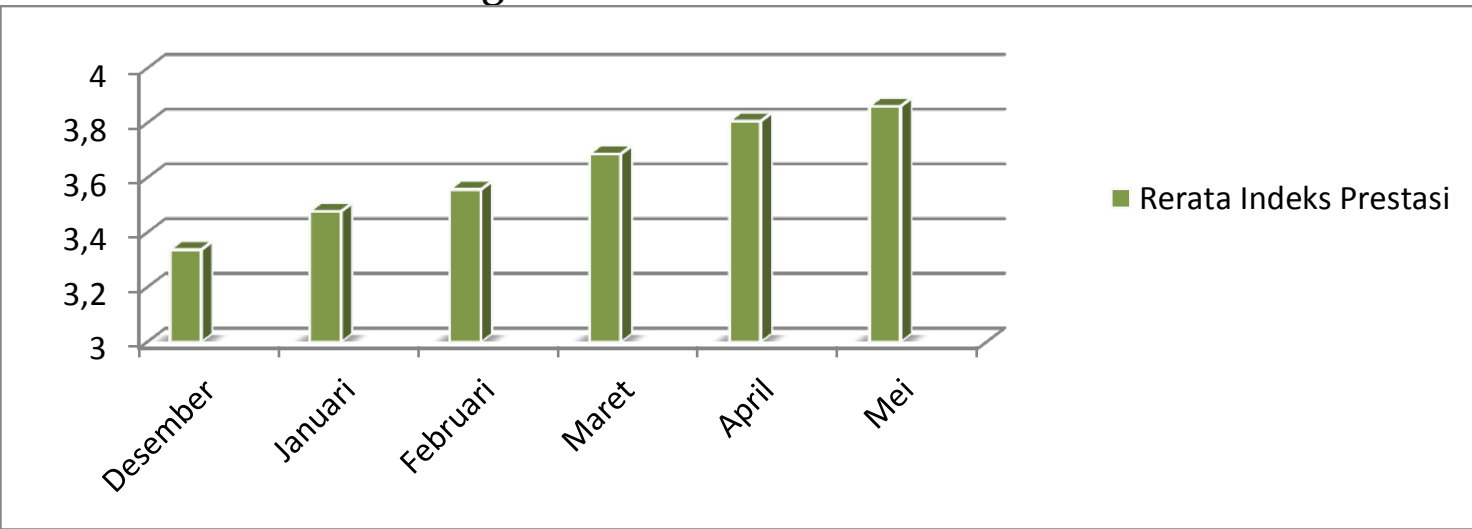


Diagram 1 di atas menunjukkan bahwa rerata indeks prestasi KPI santri SMP-SMA Integral Ar-Rohmah "Boarding School" Dau Malang mengalami peningkatan dari setiap bulannya. Hasil ini di peroleh dari penerapan teori PDCA yang dijalankan dengan baik dalam pengembangan manajemen mutu berbasis KPI.

Proses PDCA dikembangkan kedalam berbagai perpektif cara mengelola mutu, yakni konsep: a) pengendalian mutu (quality control); b) penjaminan mutu (quality asssurance); dan c) peningkatan mutu (quality improvement). Konsep pengendalian mutu dalam pendidikan merupakan kegiatan untuk mendeteksi produk pendidikan yang menyimpang dari standar yang telah ditentukan. Pengendalian mutu lebih berorientasi pada produk, yakni hasil belajar sebagai tujuan dari pendidikan atau jasa pendidikan. Learning outcome dideskripsikan berdasarkan kelulusan, kompetensi inti, dan kompetensi dasar yang merupakan acuan dalam menyatakan mutu (Aziz, 2015). Pada konsep penjaminan mutu, tidak hanya fokus pada akhir layanan atau jasa pendidikan (Hefniy \& Fairus, 2019), namun melakukan penjaminan mutu dilakukan saat kegiatan pendidikan berlangsung. Sedangkan konsep peningkatan mutu adalah kombinasi dari upaya pengendalian mutu dan penjaminan mutu yang diperluas dengan upaya-upaya peningkatan (Mucktiany et al., 2015; Jagadeesh, 2000).

Implementasi teori PDCA dalam pengembangan manajemen mutu berbasis KPI dijalankan dengan baik. Sehingga menjadikan hasil yang diperoleh dari penerapan teori PDCA berbasis KPI bisa meningkatkan target yang ingin dicapai oleh lembaga khususnya membentuk santri SMP-SMA Integral Ar-Rohmah "Boarding School” menjadi santri berkarakter Insan Kamil dengan variabel; Ruhiyah (aqidah sohihah, akhlaqul karimah, mujiddun fil ibadah, dakwah bil hikmah) dan Jismiyah (pandu hidayatullah, kedisiplinan, dan bia'ah bahasa $a r a b)$.

\section{KESIMPULAN}

Dari pemaparan data di atas dapat disimpulkan bahwa SMP-SMA Integral Ar-Rohmah "Boarding School" Dau Malang telah mengimplementasikan teori P.D.C.A dalam pengembangan manajemen mutu berbasis KPI (Key Performance Indicators). Perencanaan yang telah dilakukan yaitu dengan membuat rumusan KPI. Perumusan KPI ini dilakukan pada semester ganjil tahun ajaran 2018/2019. Penerapan dari perumusan KPI dilakukan pada semester genap tahun ajaran 2018/2019. Hasil dari penelitian ini dapat disimpulkan bahwa; Perencanaan (Plan), menghasilkan tiga produk perumusan KPI, yakni; a) monitoring KPI; b)rumus pengisian KPI; dan c) rapot KPI. Pelaksanaan (Do), dengan mewajibkan seluruh santri untuk berpartisipasi dalam pengisian form monitoring KPI serta keaktifan musyrif kamar dalam mendampingi pengisian KPI. Evaluasi (Check) yang telah dilakukan adalah dengan cara pengecekan acak (random) yang dilakukan musyrif kamar dari hasil pengisian monitoring KPI. Tindak lanjut (Act) dengan menerbitkan raport KPI. 


\section{DAFTAR PUSTAKA}

Asare, O., E, A., Longbottom, D., \& Chourides, P. (2007). Managerial Leadership for Total Quality Improvement in UK Higher Education. TQM Magazine, 19(6), 541-560. https:// doi.org/10.1108/09544780710828403

Asy'ari, H. (2015). Perbandingan Sistem Manajemen Mutu ISO 9001: 2008, Standard BAN- PT dan Total Quality Management di UIN Maulana Malik Ibrahim Malang. Jurnal Pendidikan Islam, 4(1), 141-157.

Aziz, A. (2015). Peningkatan Mutu Pendidikan. Jurnal Studi Islam, 10(2), 1-13.

Dessler, G. (2003). Manajemen Sumber Daya Manusia. Jakarta: PT Indeks Kelompok Gramedia.

Dewi, A. P. (2014). Analisis Pengendalian Kualitas dengan Pendekatan P.D.C.A. (Plan-Do-Check-Act) Berdasarkan Standar Minimal Pelayanan Rumah Sakit Pada RSUD Dr. Adhyatma Semarang (Studi Kasus pada Instalasi Radiologi). Jurnal Ilmu Administrasi Bisnis, 3(1), 216-227.

Grover, N. A. N. (2015). Measuring Retail Supply Chain Performance: Theoretical Model Using Key Performance Indicators (KPIs). Benchmarking: An International Journal, 22(1), 135-166.

Hefniy, \& Fairus, R. N. (2019). Manajemen Strategi dalam Meningkatkan Mutu Pelayanan Kepegawaian. Al- Tanzim: Jurnal Manajemen Pendidikan Islam, 3(1), 169-197.

Jagadeesh, R. (2000). Assuring Quality in Management Eeducation: The Indian Context. Quality Assurance in Education, 8(3), 110-119.

Makin, B. \& M. (2010). Manajemen Pendidikan Islam: Tranformasi Menuju Sekolah atau Madrasah Unggul. Malang: UIN Maliki Press.

Marr, B. (2015). Key Performance Indikators yang Harus diKetahui. Jakarta: PT. Elex Media Komputindo.

Mucktiany, Sani, A., Abdullah, R., \& Pramuniati, I. (2015). Penjaminan Mutu Sekolah. Jakarta: Bumi Aksara.

Muhaimin. (2015). Manajemen Pendidikan (Aplikasinya dalam Penyusunan Rencana Pengembangan Sekolah/Madrasah). Jakarta: Kencana.

Mulyasa, E. (2011). Manajemen dan Kepemimpinan Kepala Sekolah. Jakarta: PT Bumi Aksara.

Peat, M., Taylor, C. E., \& Franklin, S. (2005). Re-engineering of Undergraduate Science Curricula to Emphasise Development of Lifelong Learning Skills. Innovations in Education and Teaching International, 42(4), 135-146.

Raine Isaksson, Jonas Hansson, R. G. (2007). National Process of Quality Management Education: The Swedish Example. Asian Journal on Quality, $8(2), 101-112$.

Sagala, S. (2007). Manajemen Strategik dalam Peningkatan Mutu Ppendidikan. Bandung: Alfabeta.

Sallis, E. (2017). Manajemen Mutu Terpadu Pendidikan; Peran Strategis Pendidikan di Era Globalisasi Modern. Yogyakarta: IRCISod.

Sukmadinata, N. S. (2011). Metode Penelitian Pendidikan. Bandung: PT. Rosdakarya. 
Tannady, H. (2015). Pengendalian Kualitas. Yogyakarta: Graha Ilmu.

Tannady, H., Tannady, H., Ismuhadjar, \& Zami, A. (2019). The Effect of Organizational Culture and Employee Engagement on Job Performance of Healthcare Industry in Province of Jakarta, Indonesia. Quality: Access to Success, 20(169), 18-22.

Wadongo, B., Odhuno, E., Kambona, O., \& Othuon, L. (2010). Key performance Indicators in the Kenyan Hospitality Industry: a Managerial Perspective. Benchmarking: An International Journal, 17(6), 858-875.

Yeravdekar, S., \& Behl, A. (2017). Benchmarking Model for Management Education in India: A Total Interpretive Structural Modeling Approach. Benchmarking, 24(3), 666-693. https:/ / doi.org/10.1108/BIJ-06-2016-0082 